Supporting information for:

\title{
Rapid Topochemical Modification of Layered Perovskites via Microwave Reactions
}

Sara Akbarian-Tefaghi, Elaine Teixeira Veiga, Guillaume Amand, and John B. Wiley*

Department of Chemistry and Advanced Materials Research Institute, University of New Orleans, New Orleans, LA 70148 
Figure S1. (a) Milestone's StartSYNTH Labstation and (b) parts of a 15-bar pressure reactor used in modification reactions of the perovskite hosts.

Figure S2. Raman spectra provided for the hybrids based on HLN and HCT.

Figure S3. a) TGA and b) DSC curves for n-alkoxy-LN and c) TGA and d) DSC curves for nalkylamine-LN.

Figure S4. Results on topochemical modification of RPN host, isostructural with RLN.

Figure S5. Comparing four different hybrids based on (a) HLN host, prepared either from (b) intermediates or (c) straight from HLN.

Figure S6. HCN-based hybrids; (a) HCN, (b) methoxy-CN, and (c-h) n-alkylamine-CN.

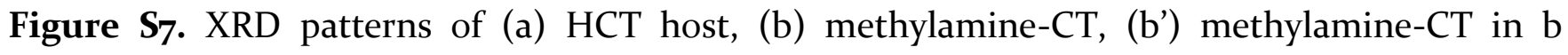
retreated with fresh methylamine, (c) ethylamine-CT with a broad first peak, and (c') ethylamineCT with a shouldered first peak.

Figure S8. XRD patterns of five amine-intercalated products based on HLT host (a), $\mathrm{C}_{\mathrm{n}} \mathrm{H}_{2 \mathrm{n}+1} \mathrm{NH}_{2}$-LT, where $\mathrm{n}=1,3,4,6$, and 8 for (b), (c), (d), (e) and (f), respectively.

Figure S9. Relationship between the c parameter of the hybrid and the number of the carbons in the alkyl chains, calculated for (a) n-alkoxy-LN, (b) n-alkylamine-LN, (c) n-alkoxy-CT, and (d) nalkylamine-CT.

Figure S1o. The schematic model of n-propoxy-CT product.

Table S1. Interlayer spacings relative to the approximation lengths of the organic substituents.

Abbreviations: $\mathrm{LN}=\mathrm{LaNb}_{2} \mathrm{O}_{7} ; \mathrm{PN}=\mathrm{PrNb}_{2} \mathrm{O}_{7} ; \mathrm{CN}=\mathrm{Ca}_{2} \mathrm{Nb}_{3} \mathrm{O}_{10} ; \mathrm{CT}=\mathrm{CaTa}_{2} \mathrm{O}_{7} ; \mathrm{LT}=\mathrm{La}_{2} \mathrm{Ti}_{3} \mathrm{O}_{10}$ 
Figure S1(a) shows Milestone's START platform (StartSYNTH Microwave Synthesis Labstation) and Figure S1(b) represents the parts of a microwave pressure reactor ( $<15$ bar).

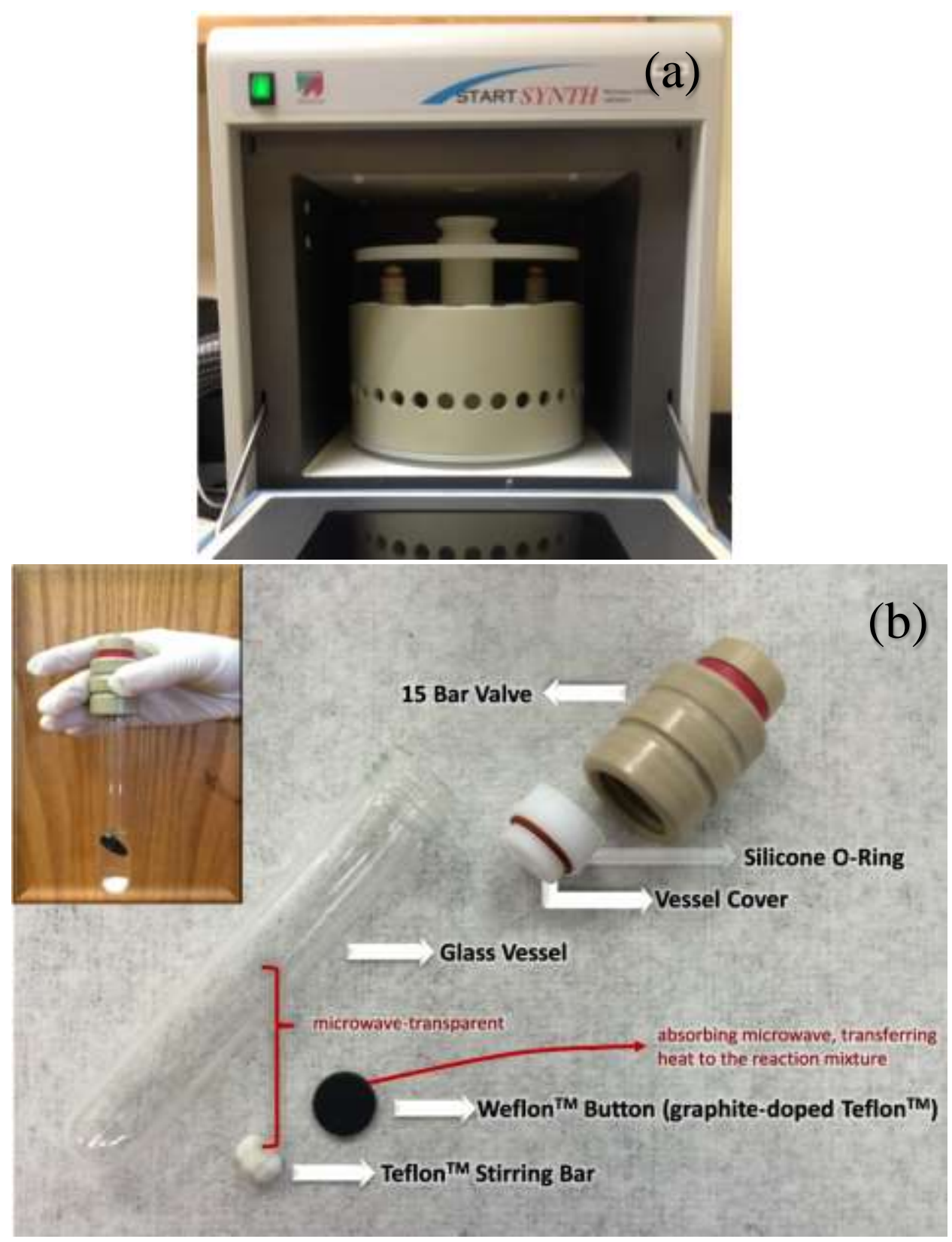

Figure S 1. (a) Milestone's StartSYNTH Labstation and (b) parts of a 15-bar pressure reactor used in modification reactions of the perovskite hosts. 
Figure S2 presents the Raman spectra for the hybrids based on (a) HLN and (b) HCT.
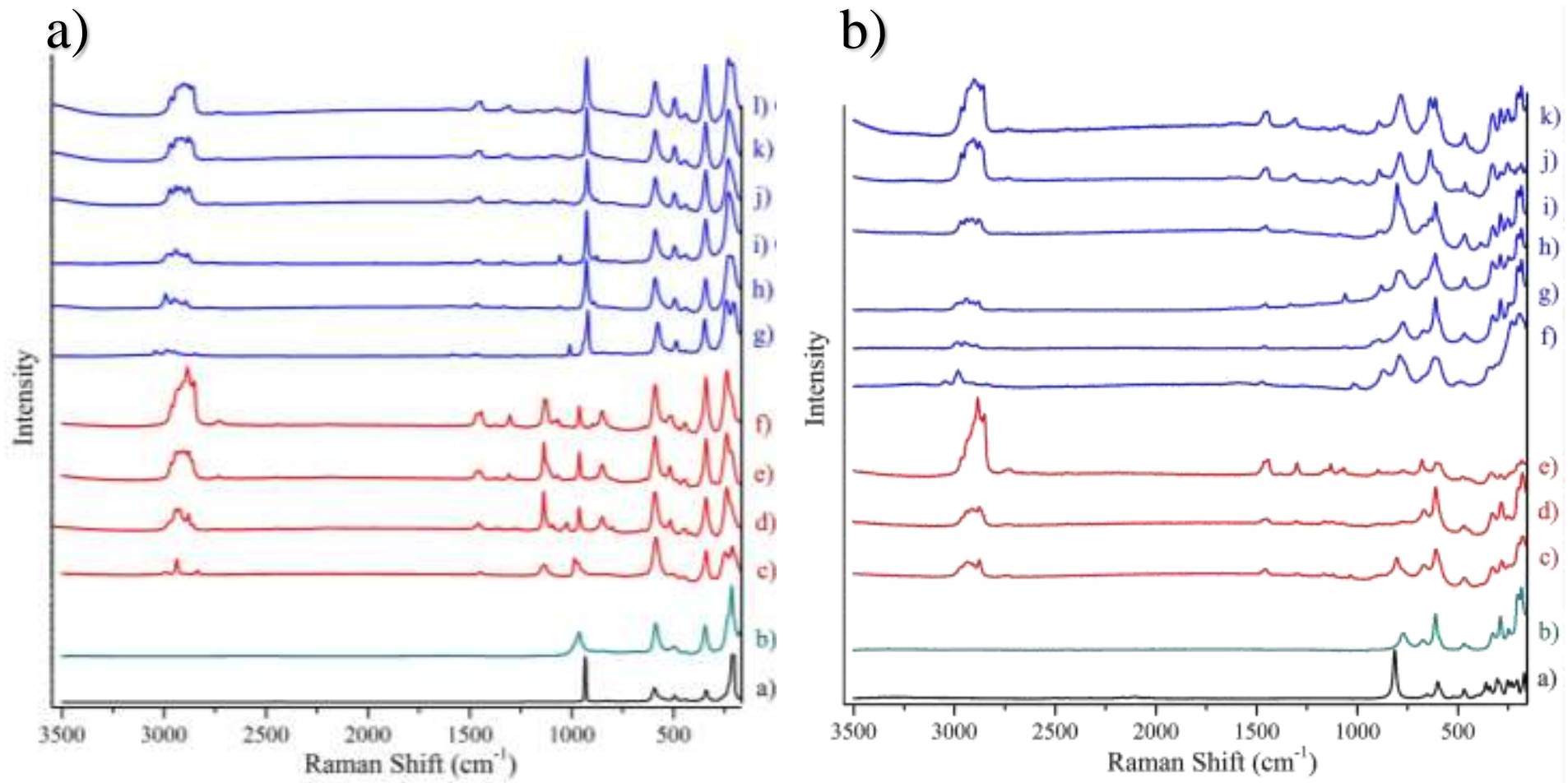

Figure S2. Raman spectra provided for the hybrids based on HLN and HCT.

a) RLN-based products: (a) RLN, (b) HLN, (c-f) n-alkoxy-LN $\left(\mathrm{C}_{n} \mathrm{H}_{2 n+1}-\mathrm{LaNb}_{2} \mathrm{O}_{7}\right.$ where $\mathrm{n}=1,3,5$ and 10 in c, d, e and $\mathrm{f}$ respectively) and (g-l) n-alkylamine- $\mathrm{LN}\left(\mathrm{C}_{\mathrm{n}} \mathrm{H}_{2 \mathrm{n}+1} \mathrm{NH}_{2}-\mathrm{LaNb}_{2} \mathrm{O}_{7}\right.$ where $\mathrm{n}=1,2,3,4,6$ and $8 \mathrm{in} \mathrm{g}, \mathrm{h}, \mathrm{i}, \mathrm{j}, \mathrm{k}$ and $\mathrm{l}$ respectively).

b) LCT-based products: (a) LCT, (b) HCT, (c-e) n-alkoxy-CT $\left(\mathrm{C}_{\mathrm{n}} \mathrm{H}_{2 \mathrm{n}+1}-\mathrm{CaTa}_{2} \mathrm{O}_{7}\right.$ where $\mathrm{n}=3,5$ and 10 in c, d and e respectively) and (f-k) n-alkylamine-CT $\left(\mathrm{C}_{n} \mathrm{H}_{2 n+1} \mathrm{NH}_{2}-\mathrm{CaTa}_{2} \mathrm{O}_{7}\right.$ where $\mathrm{n}=1,2,3,4,6$ and $8 \mathrm{in} \mathrm{f}, \mathrm{g}, \mathrm{h}, \mathrm{i}, \mathrm{j}$ and $\mathrm{k}$ respectively). 
TGA-DSC results for the entire series of HLN-based hybrids are provided in Figure $\mathbf{S}_{\mathbf{3}}$, a) TGA and b) DSC curves for n-alkoxy-LN and c) TGA and d) DSC curves for n-alkylamine-LN.
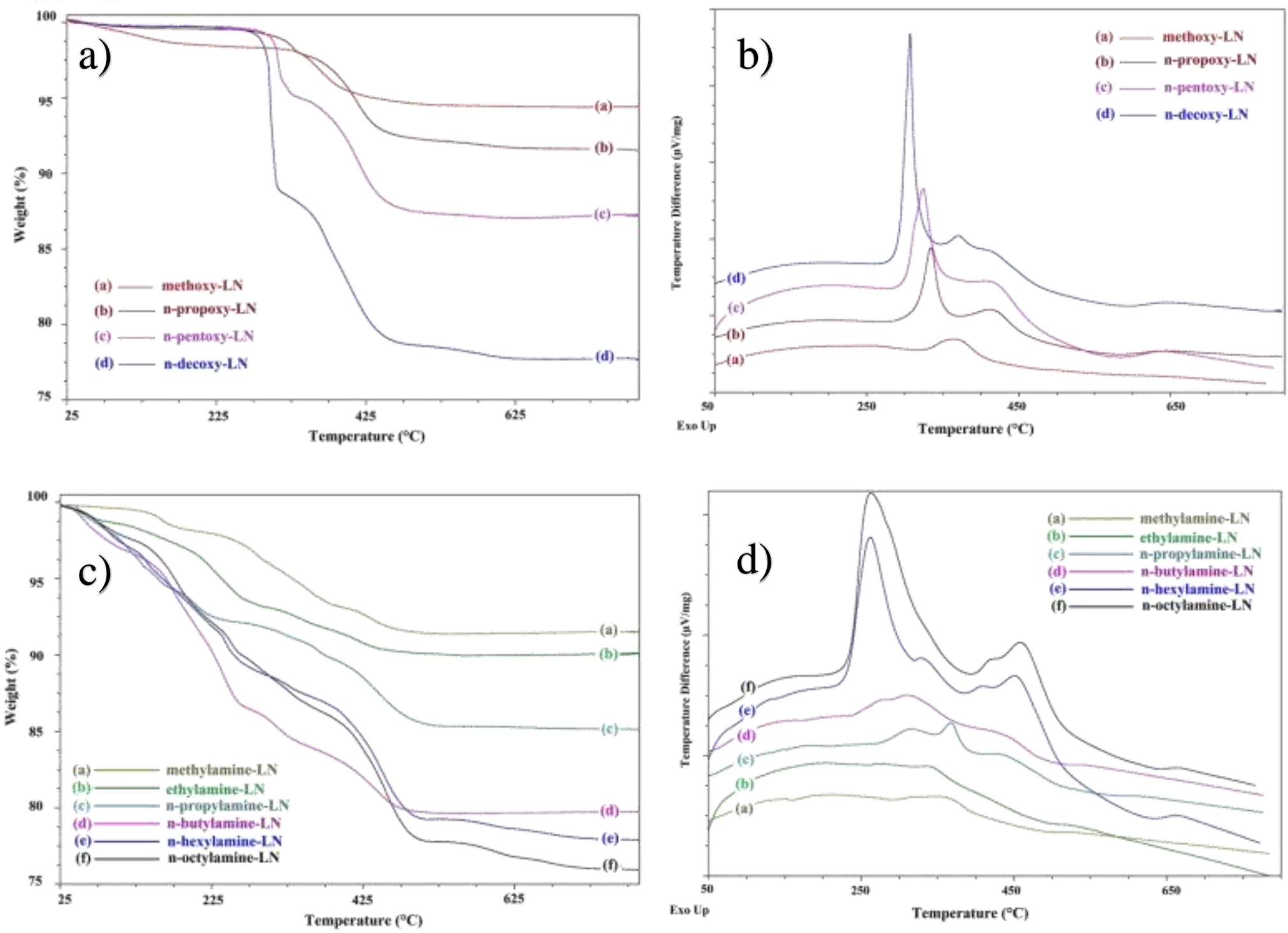

Figure S3. a) TGA and b) DSC curves for n-alkoxy-LN and c) TGA and d) DSC curves for n-alkylamine-LN. 
Table S1. Interlayer spacings relative to the approximation lengths of the organic substituents.

\begin{tabular}{|c|c|c|c|c|}
\hline \multicolumn{2}{|r|}{ Compound } & c parameter $(\AA)$ & $\Delta \mathbf{c}(\AA)$ * & $\begin{array}{c}\text { Approximate Chain } \\
\text { Length }(\AA) * *\end{array}$ \\
\hline \multicolumn{2}{|r|}{$\mathrm{RbLaNb}_{2} \mathrm{O}_{7}$} & $10.9626(3)$ & & \\
\hline \multicolumn{2}{|r|}{$\mathrm{HLaNb}_{2} \mathrm{O}_{7}$} & $10.4527(5)$ & & \\
\hline $\mathrm{CH}_{3} \mathrm{O}-$ & methoxy-LN & $23.0579(5)$ & 1.0763 & 2.5 \\
\hline $\mathrm{C}_{3} \mathrm{H}_{2} \mathrm{O}-$ & n-propoxy-LN & $15.4011(5)$ & 4.9484 & 5 \\
\hline $\mathrm{C}_{5} \mathrm{H}_{11} \mathrm{O}-$ & n-pentoxy-LN & $18.5051(9)$ & 8.0524 & $7 \cdot 5$ \\
\hline $\mathrm{C}_{10} \mathrm{H}_{21} \mathrm{O}-$ & n-decoxy-LN & $27.2380(6)$ & 16.7853 & 14 \\
\hline $\mathrm{CH}_{3} \mathrm{NH}_{2}$ & methylamine-LN & $12.1073(6)$ & 1.6546 & $3 \cdot 5$ \\
\hline $\mathrm{C}_{2} \mathrm{H}_{5} \mathrm{NH}_{2}$ & ethylamine-LN & $16.5819(2)$ & 6.1292 & 5 \\
\hline $\mathrm{C}_{3} \mathrm{H}_{7} \mathrm{NH}_{2}$ & n-propylamine-LN & $18.3316(2)$ & 7.8789 & 6 \\
\hline $\mathrm{C}_{4} \mathrm{H}_{2} \mathrm{NH}_{2}$ & n-butylamine-LN & $20.9230(3)$ & 10.4703 & $7 \cdot 5$ \\
\hline $\mathrm{C}_{6} \mathrm{H}_{13} \mathrm{NH}_{2}$ & n-hexylamine-LN & $24.7800(6)$ & $14 \cdot 3273$ & 10 \\
\hline $\mathrm{C}_{8} \mathrm{H}_{17} \mathrm{NH}_{2}$ & n-octylamine-LN & $28.3872(7)$ & 17.9345 & 12.5 \\
\hline \multicolumn{2}{|r|}{$\mathrm{Li}_{2} \mathrm{CaTa}_{2} \mathrm{O}_{7}$} & $18.193(6)$ & & \\
\hline \multicolumn{2}{|r|}{$\mathrm{H}_{2} \mathrm{CaTa}_{2} \mathrm{O}_{7}$} & $18.242(6)$ & & \\
\hline $\mathrm{C}_{3} \mathrm{H}_{2} \mathrm{O}-$ & n-propoxy-CT & $17.25(1)$ & 8.13 & 5 \\
\hline $\mathrm{C}_{5} \mathrm{H}_{11} \mathrm{O}-$ & n-pentoxy-CT & $20.75(2)$ & 11.63 & $7 \cdot 5$ \\
\hline $\mathrm{C}_{10} \mathrm{H}_{21} \mathrm{O}-$ & n-decoxy-CT & $34.16(3)$ & 15.92 & 14 \\
\hline $\mathrm{CH}_{3} \mathrm{NH}_{2}$ & methylamine-CT & $11.705(7)$ & 2.58 & 3.5 \\
\hline $\mathrm{C}_{2} \mathrm{H}_{5} \mathrm{NH}_{2}$ & ethylamine-CT & $15.06(2)$ & 5.94 & 5 \\
\hline $\mathrm{C}_{3} \mathrm{H}_{7} \mathrm{NH}_{2}$ & n-propylamine-CT & $17.930(9)$ & 8.81 & 6 \\
\hline $\mathrm{C}_{4} \mathrm{H}_{9} \mathrm{NH}_{2}$ & n-butylamine-CT & $20.64(1)$ & 11.52 & $7 \cdot 5$ \\
\hline $\mathrm{C}_{6} \mathrm{H}_{13} \mathrm{NH}_{2}$ & n-hexylamine-CT & $24 \cdot 51(2)$ & 15.39 & 10 \\
\hline $\mathrm{C}_{8} \mathrm{H}_{17} \mathrm{NH}_{2}$ & n-octylamine-CT & $27 \cdot 33(2)$ & 18.21 & 12.5 \\
\hline
\end{tabular}

*relative to the proton exchange material

** estimated using Chem3D Ultra CambridgeSoft software 


\section{$\mathrm{RbPrNb}_{2} \mathrm{O}_{7}$}

$\mathrm{RbPrNb}_{2} \mathrm{O}_{7}$ (RPN) is a double-layered Dion-Jacobson perovskite, isostructural with RLN host, that was recently synthesized and reported by Montasserasadi et al. ${ }^{1}$ RPN was prepared exactly as reported ${ }^{1}$ and was treated with nitric acid the same as RLN host. $\mathrm{HPrNb}_{2} \mathrm{O}_{7}(\mathrm{HPN})$, which is being reported here for the first time (Figure $\mathrm{S}_{4} \mathrm{a}$ ), was successfully prepared via microwave-assisted protonation of RPN. Some of the organic modification reactions that were done on RLN, were repeated on RPN host with the exact same experimental procedures $\left(C_{n} H_{2 n+1}-P N, n=1,3\right.$ and $\mathrm{C}_{\mathrm{n}} \mathrm{H}_{2 \mathrm{n}+1} \mathrm{NH}_{2}-\mathrm{PN}, \mathrm{n}=1,3,4,6,8$ in Figure $\left.\mathrm{S} 4 \mathrm{~b}\right)$. As HPN is a new compound, HPN-based organic hybrids have also not been previously reported in the literature. Since RPN and RLN hosts are isostructural, as expected, very similar behavior was observed. It is notable that these 7 trials were randomly done to confirm similar chemistry between HLN and HPN isostructural compounds, it is expected that all the other reactions not attempted on HPN should show similar behavior to HLN (n-pentanol, n-decanol and ethylamine).
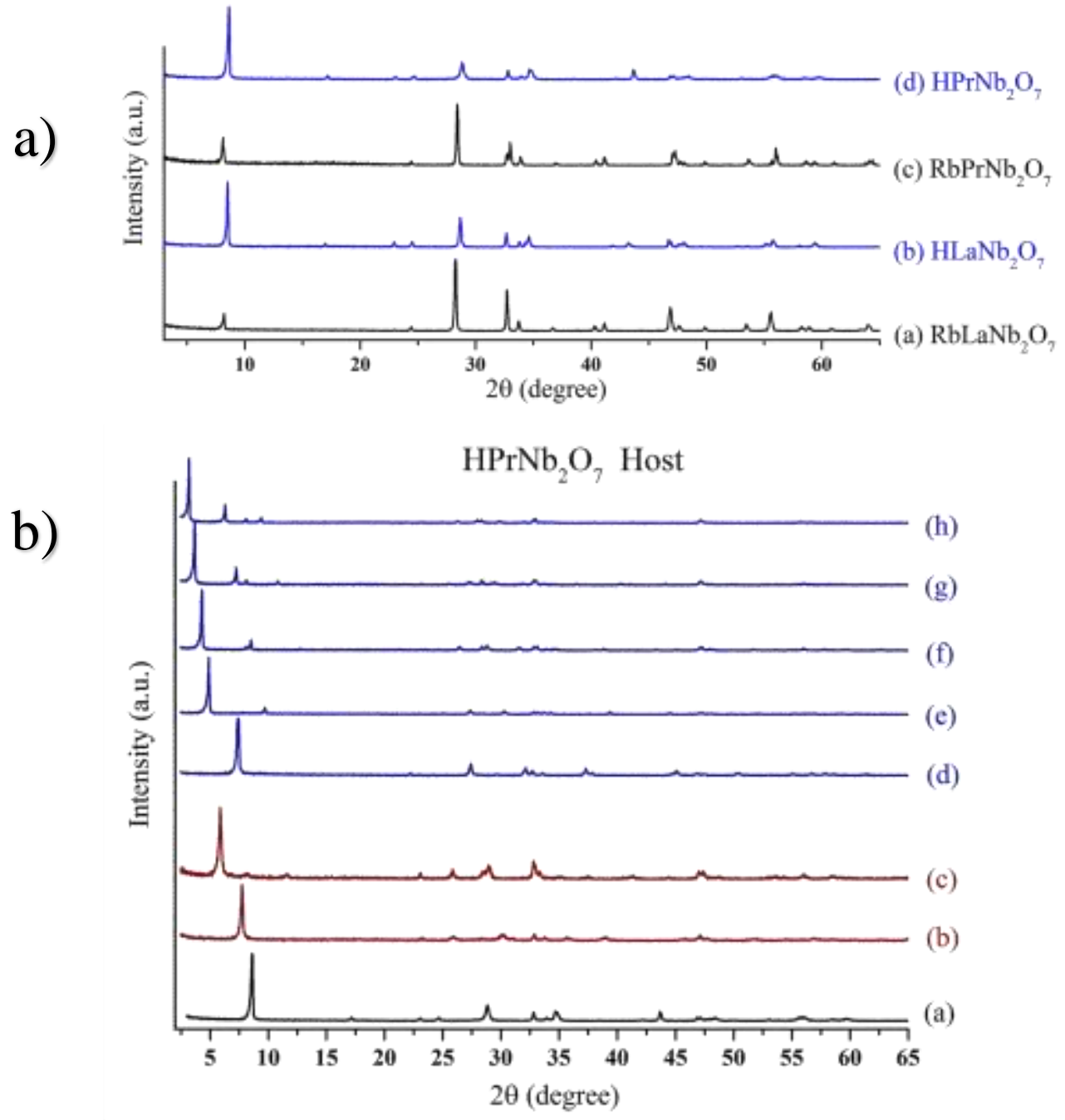

Figure $S_{4}$. Results on topochemical modification of RPN host, isostructural with RLN.

a) Comparing the XRD patterns of RPN and HPN with RLN and HLN; (a) RLN, (b) HLN, (c) RPN, and (d) HPN.

b) HPN-based hybrids; (a) HPN, (b, c) $\mathrm{C}_{n} \mathrm{H}_{2 n+1}-\mathrm{PN}$ ( $\mathrm{n}=1$ and 3 for b and c respectively), and (d-h) $\mathrm{C}_{n} \mathrm{H}_{2 n+1} \mathrm{NH}_{2}-\mathrm{PN}$ $(\mathrm{n}=1,3,4,6$, and 8 in $\mathrm{d}, \mathrm{e}, \mathrm{f}, \mathrm{g}$ and $\mathrm{h}$, respectively). 
Figure $\boldsymbol{S}_{\mathbf{5}}$ provides the XRD patterns of n-pentoxy-LN, n-decoxy-LN, n-hexylamine-LN and noctylamine-LN products from two different synthetic pathways, either starting straight from HLN host $\left(\mathrm{S}_{5}-\mathrm{a}\right)$ or using a shorter organic-grafted/intercalated intermediate (n-propoxy-LN and nbutylamine-LN intermediates for n-alkoxy-LN and n-alkylamine LN products, respectively). Starting straight from HLN (Figure $5 \mathrm{c}$ ) leads to partial grafting/intercalation and unreacted HLN (peaks marked with solid squares). Proceeding through an intermediate organic substituent (Figure $5 \mathrm{~b}$ ) leads to a much better quality product.

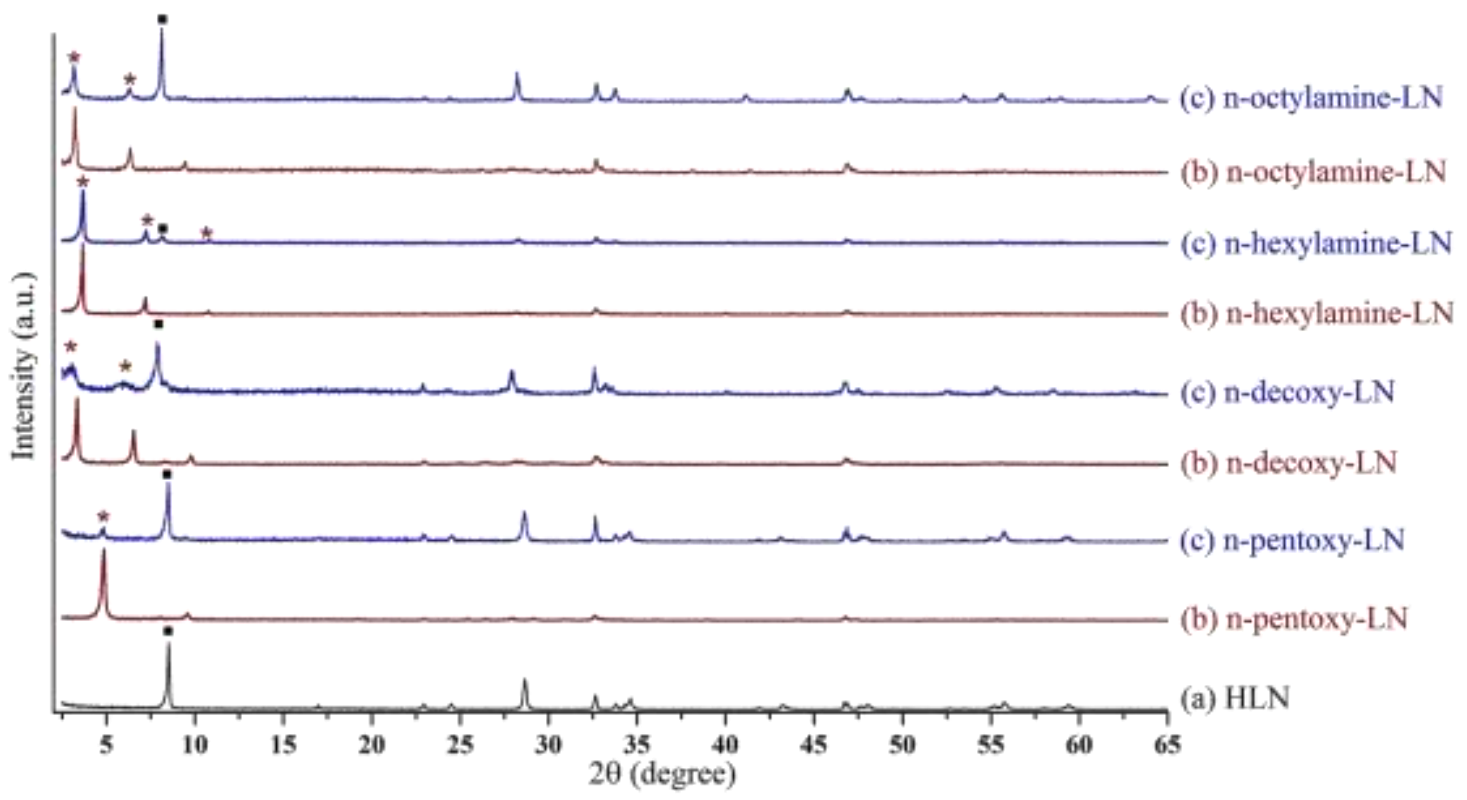

Figure S5. Comparing four different hybrids based on (a) HLN host, prepared either from (b) intermediates or (c) straight from HLN

- Square peaks indicate the incompletion of the reaction due to the presence of HLN starting material.

* Star peaks highlight the existence of the target products provided in (b), in spite of the incomplete reactions in (c). 
Figure S6 presents the XRD patterns of organic-inorganic hybrids prepared from HCN.

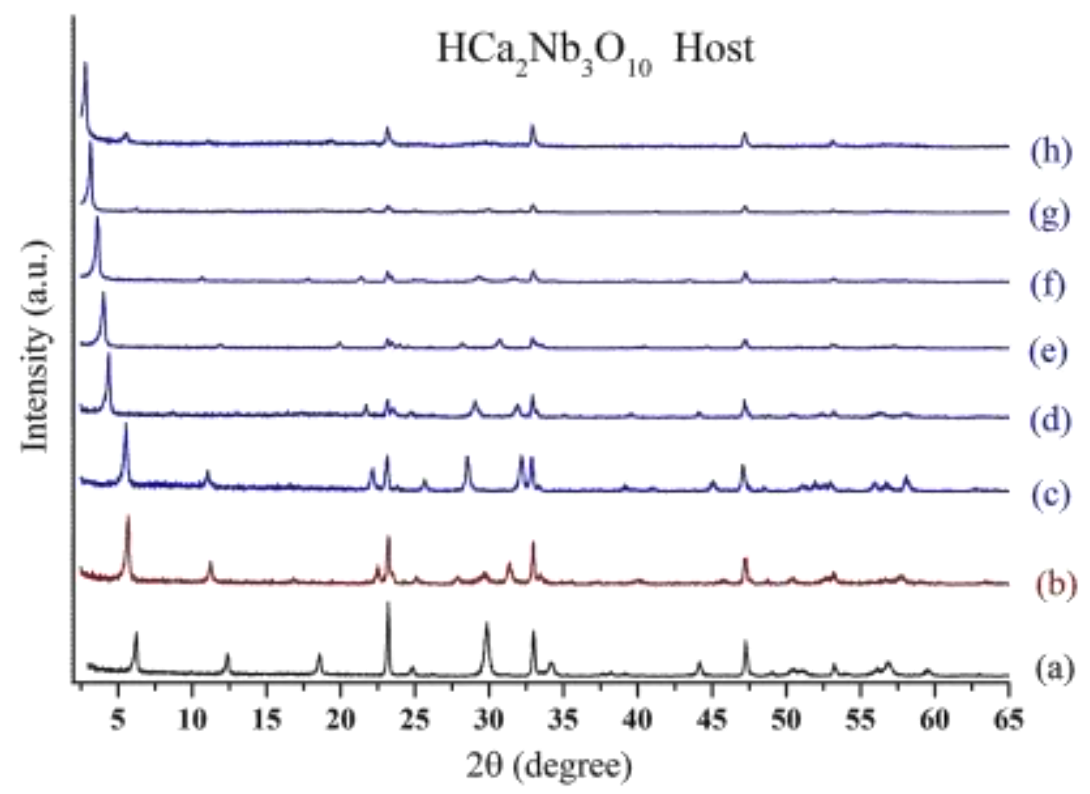

Figure S6. HCN-based hybrids; (a) HCN, (b) methoxy-CN, and (c-h) n-alkylamine-CN $\left(C_{n} H_{2 n+1} N_{2}-C N\right.$, where $n=1,2,3,4,6$, and 8 for $c, d, e, f$, $g$ and $h$, respectively).

The XRD patterns of methylamine-CT and ethylamine-CT (Figure $\mathbf{S}_{7}$ ) exhibit additional reflections depending on treatment (reflections marked with star, *). For methylamine-CT (b), the lower angle peak of the first shouldered reflection decreases in intensity after retreating the same sample with fresh methylamine (b'). In case of ethylamine-CT, the first peak is either broader than the other hybrids prepared from HCT host where $\mathrm{n} \geq 3$ (c), or shouldered (c').

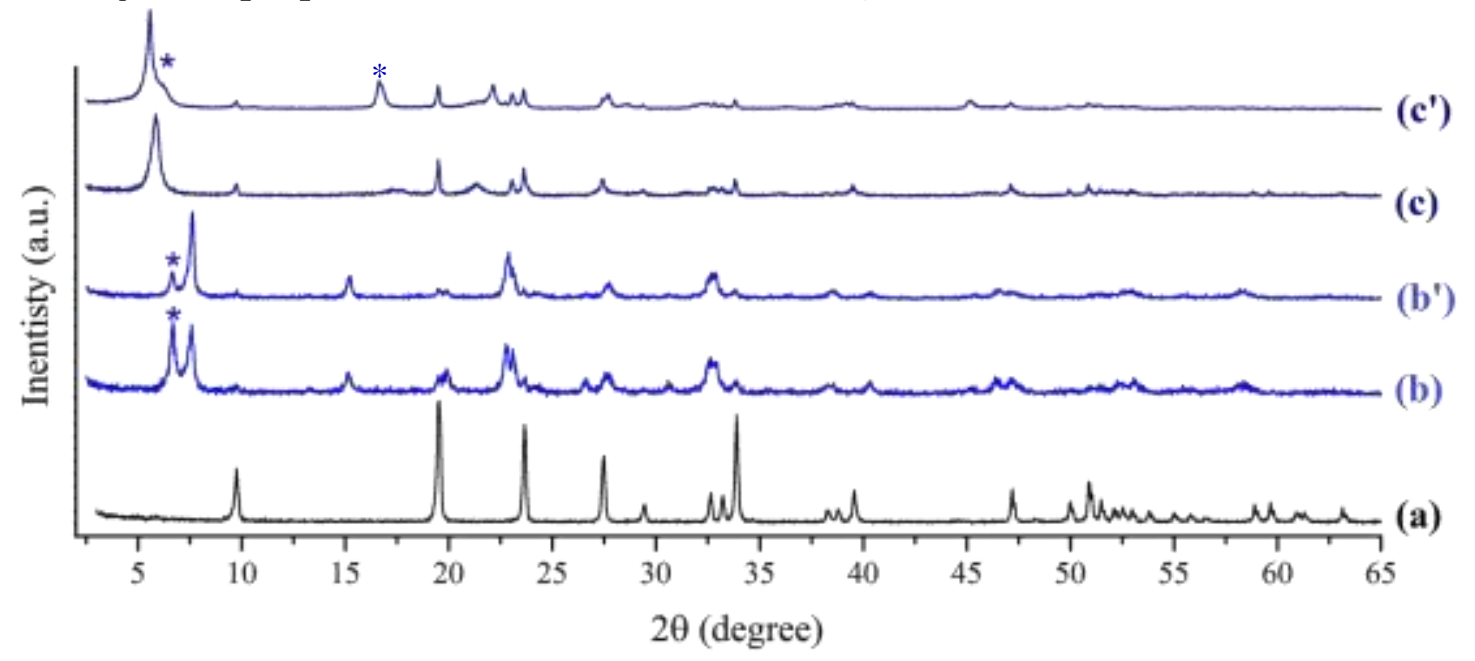

Figure $S_{7}$. XRD patterns of (a) HCT host, (b) methylamine-CT, (b') methylamine-CT in b retreated with fresh methylamine, (c) ethylamine-CT with a broad first peak, and (c') ethylamine-CT with a shouldered first peak. 
Figure S8 provides the XRD patterns of some $n$-alkylamine intercalated hybrids (b-f) based on HLT host (a). Existence of HLT in all these hybrids is clear and the XRD patterns are quite noisy, which is likely due to the poor crystallinity of these products.

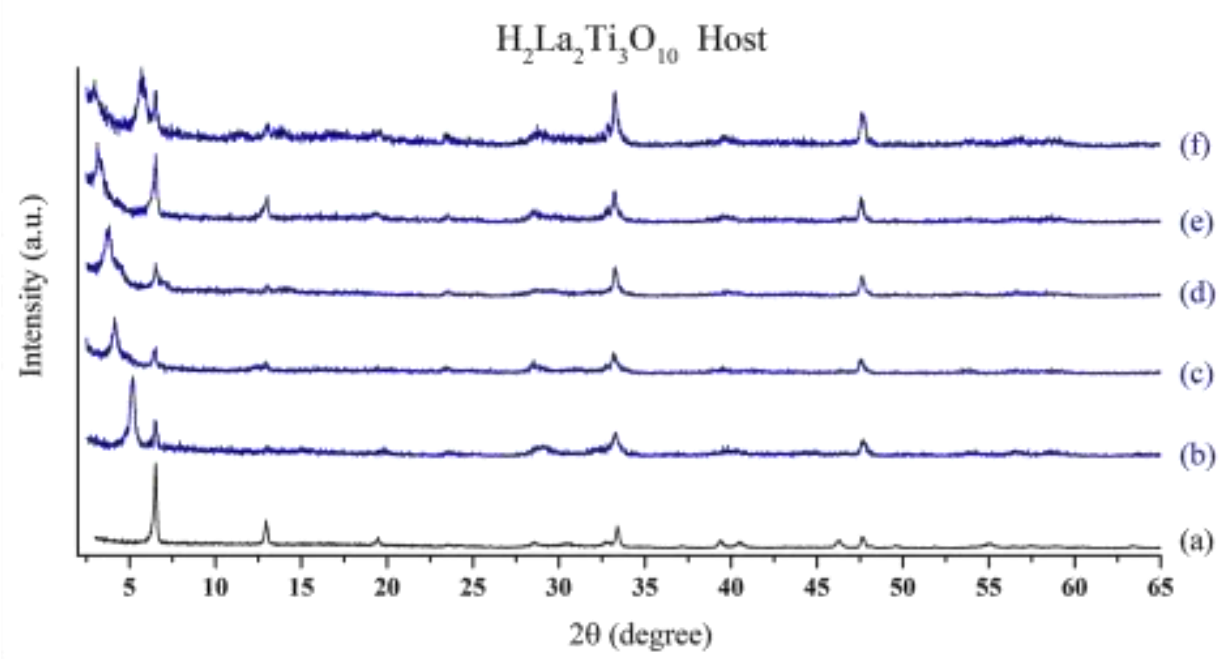

Figure S8. XRD patterns of five amine-intercalated products based on HLT host (a), $\mathrm{C}_{\mathrm{n}} \mathrm{H}_{2 \mathrm{n}+1} \mathrm{NH}_{2}$-LT, where $\mathrm{n}=1,3,4,6$, and 8 for (b), (c), (d), (e) and (f), respectively. 


\section{Tilt Angle}

The linear relationships between the number of carbon atoms $(n \geq 3)$ in the alkyl chains and the $c$ parameters of n-alkoxy and n-alkylamine hybrids based on HLN and HCT hosts are shown in Figure S9: (a) n-alkoxy-LN, (b) n-alkylamine-LN, (c) n-alkoxy-CT, and (d) n-alkylamine-CT. The slope, which is defined as the increase in the interlayer spacing per one carbon atom, was then calculated for each series. The maximum increase of all-trans monolayers of alkyl chains should be about 1.27 Å per one carbon atom (considering the all-trans configuration proved by IR and/or CP/MAS NMR spectra in the literature).$^{2-6}$ Since all the slope values are much higher than $1.27 \AA$ and smaller than $2.54 \AA(2 \times 1.27 \AA)$, the formation of tilted bilayers is suggested, similar to that reported in the literature. ${ }^{2-6}$

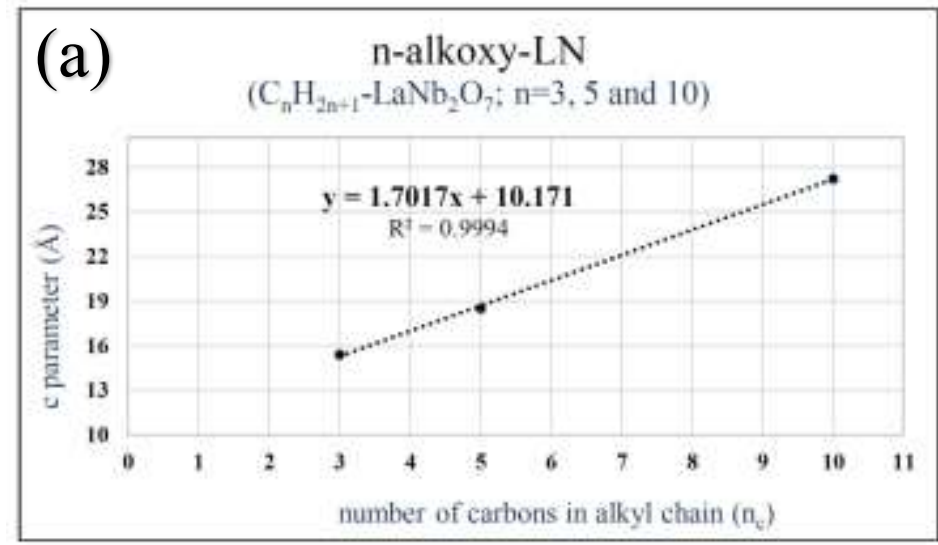

tilt angle $=\sin ^{-1}\left(\frac{1.7017}{2 \times 1.27}\right)=42^{\circ}$

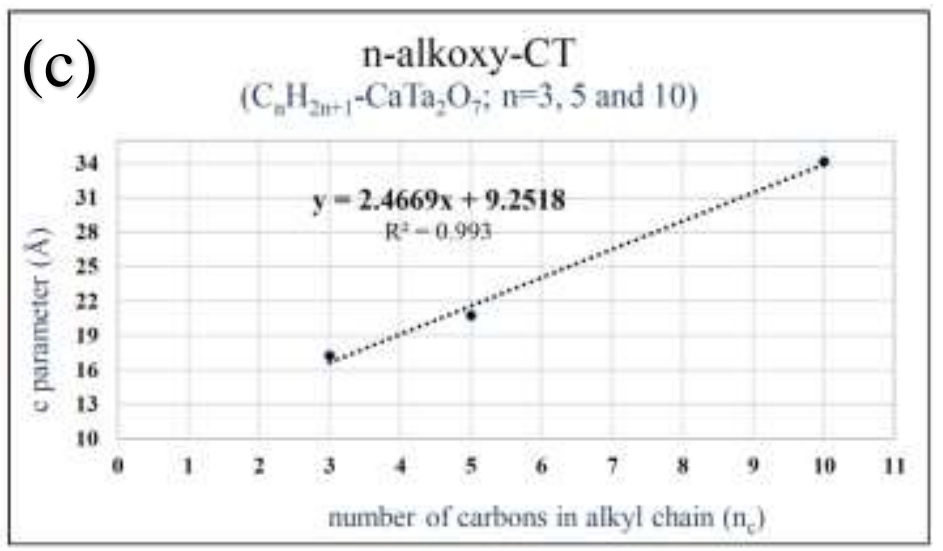

tilt angle $=\sin ^{-1}\left(\frac{2.4669}{2 \times 1.27}\right) \equiv 76^{\circ}$

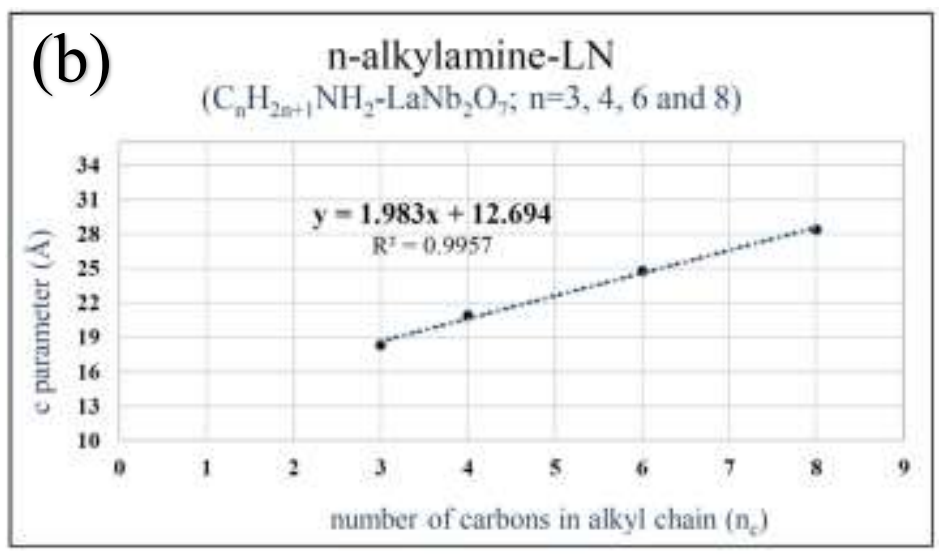

Lilt angle $=\sin ^{-1}\left(\frac{1.983}{2 \times 1.27}\right)=51^{\circ}$

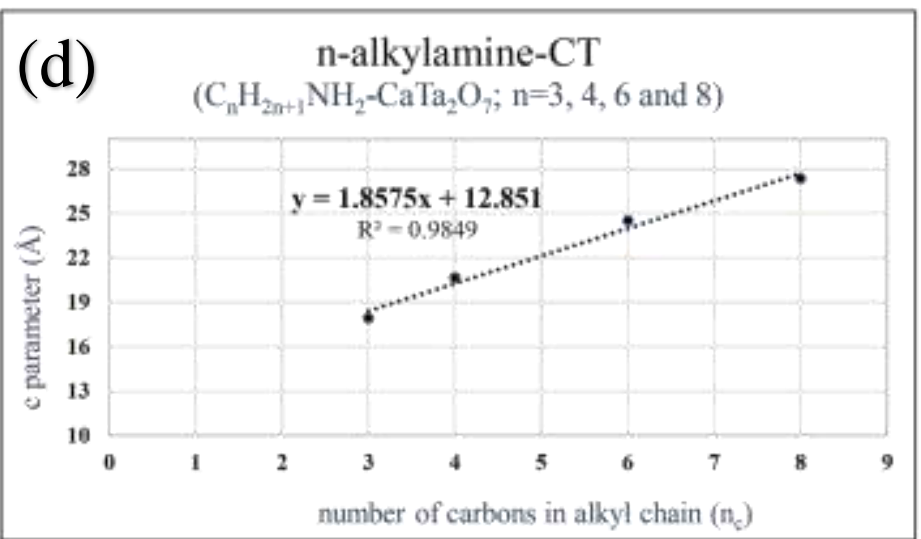

tilt angle $=\sin ^{-1}\left(\frac{1.8575}{2 \times 1.27}\right)=47^{\circ}$

Figure S9. Relationship between the c parameter of the hybrid and the number of the carbons in the alkyl chains, calculated for (a) n-alkoxy-LN, (b) n-alkylamine-LN, (c) n-alkoxy-CT, and (d) n-alkylamine-CT. 
A schematic model of n-propoxy-CT is provided in Figure S1o. It should be noted that this model is an estimation of how organics are most likely oriented in the interlayer based on the values provided in table $S_{1}$ and the tilt angles calculated in Figure S9. The tilt angle estimated for $\mathrm{n}$-alkoxy-CT is very close to what previously reported in the literature. ${ }^{4}$

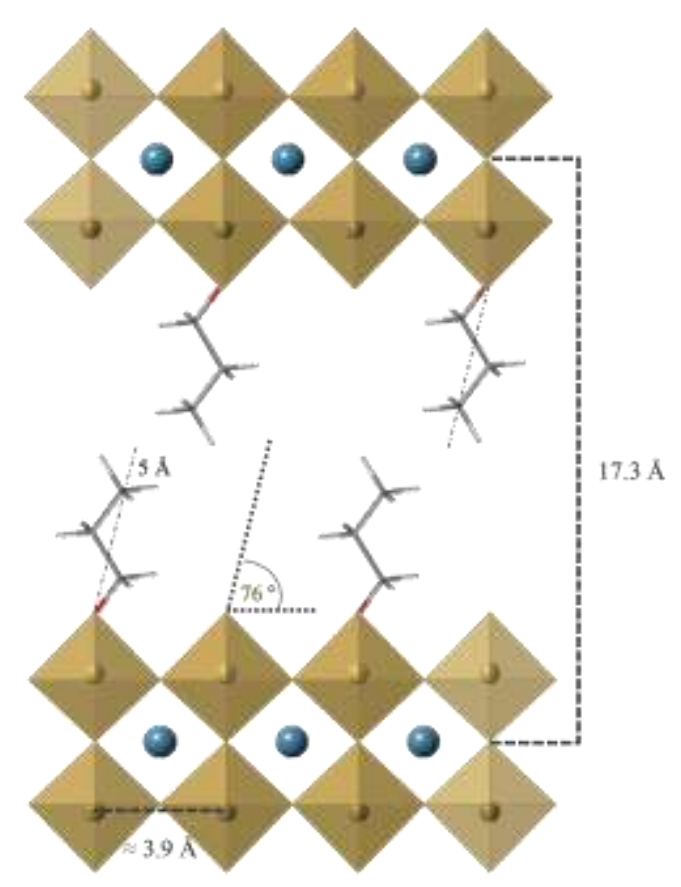

Figure S1o. The schematic model of n-propoxy-CT product. 


\section{References:}

(1) Montasserasadi, D.; Granier, M. W.; Spinu, L.; Rai, S. C.; Zhou, W.; Wiley, J. B. Dalton Trans 2015, 44, 10654-1066o.

(2) Jacobson, A. J.; Whittingham, M. S. Intercalation Chemistry; Academic Press: New York, NY, 1982.

(3) Tahara, S.; Sugahara, Y. Langmuir 2003, 19, 9473-9478.

(4) Wang, Y.; Wang, C.; Wang, L.; Hao, Q.; Zhu, X.; Chen, X.; Tang, K. RSC Adv 2o14, 4, 4047-4054.

(5) Tahara, S.; Ichikawa, T.; Kajiwara, G.; Sugahara, Y. Chem. Mater. 2007, 19, 23522358.

(6) Amghouz, Z.; Espina, A.; García, J. R. J. Solid State Chem. 2015, 221, 158-165. 